\title{
濒危植物明党参种子散布和种子库动态研究
}

\author{
盛海燕 常 杰 殷现伟 紮梅英 葛 㴻 \\ (浙江大学生命科学学院, 杭州 310029)
}

摘要：对伞形科濒危植物明党参 (Changium smyrnioides) 的种子生产、散布和种子库动态进行了研究。明党参平均 每株产生完好种子 132 粒 $86.36 \%$ 来自顶生花序, 不同生境中个体产生的种子千粒重有差异; 其平均 $1.06 \mathrm{~m}$ 高的 花葶在种子散布过程中易倒伏, 使种子远离母株, 种子散布格局为聚集型, 种子库密度随时间逐渐下降。明党参种 子产量和不同时期种子库密度均低于同科非濒危植物峨参 (Anthriscus sylvestris) ,2 个种的种子库均为非持续型; 明 党参具有低种子数、大粒种子、种子散布远离母株以减少种内竞争的 $K$ 对策, 在受到人类大量采挖和生境干扰后种 群不容易迅速恢复; 而峨参采取高种子数、小粒种子、种子近母株密集分布和产生无性系的 $r$ 对策, 种群受干扰后易 恢复。

关键词: 种子生产, 比较研究, 生态对策, 峨参

中图分类号:Q948.1文献标识码：A 文章编号 : 1005-0094(2002)03-0269-05

\section{Seed dispersal and seed bank dynamics of the endangered Changium smyr- nioides}

SHENG Hai-Yan , CHANG Jie , YIN Xian-Wei , FAN Mei-Ying , GE Ying College of Life Science, Zhejiang University , Hangzhou 310029

Abstract : Changium smyrnioides is an endangered species of Umbelliferae. Its cytology , pollen morphology , geological distribution, and genetic diversity have been studied, but the ecological characteristics of its seeds still remain unknown. To understand the mechanism of endangerment of $C$. smyrnioides, seed production and dispersal and the dynamics of its seed bank were investigated by random sampling methods. Seed production of $C$. smyrnioides is 132 seeds/individual , 86.4\% of which are from the top inflorescence. The kilo-grain weight of seeds is different between habitats. The scape (averaged $1.06 \mathrm{~m}$ in height) of $C$. smyrnioides often falls to the ground, so seeds fall far from their mother plant. The seed dispersal pattern is contagious. Compared with Anthriscus sylvestris, another species of Umbelliferae, seed production and seed bank density of $C$. smyrnioides in different periods is much less. Both seed banks are non-persistent. C. smyrnioides maintain the seed bank by multi-procreation, while A. sylvestris is maintained by clonal reproduction. C. smyrnioides has adopted a $K$-strategy, with low seed number, large seed size and dispersion far from the mother plant so as to avoid density competition among the seedlings. Therefore, when it is disturbed by humans, by digging for medicinal use and deforestation, the population cannot recover quickly. A. sylvestris has adopted a $r$-strategy, with high seed number, small seed size, dispersion near the mother plant, and production of ramets. Its population can recover quickly when it is disturbed by humans.

Key words : seed production, comparative study, ecological strategy , Anthriscus sylvestris

\section{1 引言}

种子是植物生活史中最重要的环节,从种子成 熟到幼苗建成这一过程中，种子受不同的生态因子
限制, 最终萌发或者丢失。研究种子散布的数量和 规律, 是深入研究种群动态及群落动态的基础工作, 也是研究物种的生态适应及其种群对策的基础 (杨 
允菲, 祝玲 ,1995a）。种子分布的时空格局可以在一 定程度上反映某个种地上植株的过去, 也可以预测 未来植株的分布及多度 (Hall \& Swaine ,1980)。国 外自 70 年代以来广泛进行种子散布方式、散布数 量、散布格局等方面的研究 (Berg,2000;Marchand \& Roach 1980;Platt, 1975;Sheldon \& Burrows ,1973)。 国内近年来也做了很多工作, 如群落种子库 (杨允 菲，祝玲，1995b; 唐勇等，1998;刘济明，钟章成， 2000 ;孙书存,陈灵芝，2000）, 以及种子散布格局研 究(杨允菲,祝玲 ,1995b) 等等。

明党参 (Changium smyrnioides) 为我国特有的伞 形科单种属多年生草本植物, 其根为名贵药材, 近年 来人类大量采挖, 其野生资源遭受严重破坏, 种群呈 现明显衰退倾向, 1984 年被列入国家三级重点保护 的濒危植物 (国家环保局, 中国科学院植物研究所， 1991)。现已进行了明党参细胞学、花粉形态学、生 态地理分布、遗传多样性等方面的研究(潘泽惠等， 1995 ;舒璞，佘孟兰，1990;程翔等，1993 ;邱英雄，傅 承新 2001）其中仅很少一些工作探讨了其濒危的 机制, 并且为初步结果。植物濒危的原因除了人类 过度采收、利用及对生境的破坏外, 还可能有植物自 身生物学方面的原因。为了更深一步地了解明党参 濒危的原因，我们以生态习性相近、同样作为药用植 物受到大量采挖但却没有表现出濒危趋势的峨参 (Anthriscus sylvestris) 为对照种,对其种子散布过程 及散布格局进行了研究，以期从种子生态学方面来 揭示明党参濒危的原因,为迁地保护和人工繁殖利 用提供理论依据。

\section{2 样地概况与方法}

样地选在杭州市葛岭 (只有明党参分布) 和南 高峰 (明党参、峨参均有分布)。葛岭样地主要位于 落叶阔叶林和竹林下, 南高峰样地位于落叶阔叶林 下和林缘。落叶阔叶林下的明党参伴生植物有络石 ( Trachelospermum jasminoides)、蓬葙 (Rubus hirsu$t u s)$ 、常春藤 (Hedera helix)、金㭴子 (Rosa laeviga$t a$ )、冷水花 (Pilea notata)、牛膝 (Achyranthes bident$a t a)$ 、接骨草 (Sambucus chinensis)、天葵 (Semiaquilegia adoxoides)、珠芽尖距紫堇 (Corydalis sheareri)、 荩草 (Arthraxon hispidus) 等。竹林下伴生植物较少， 仅有络石、紫堇等。峨参样地位于南高峰林缘和路 边水分较充足的地方, 主要伴生种有野菩薇 (Rosa multiflora) 、高粱泡 (Rubus lambertianus)、络石、接骨 草、野芝麻 (Lamium barbatum) 、还亮草 (Delphinium anthriscifolium) 等。

\section{1 种子产量研究方法}

2001 年 6 月初,在明党参、峨参种子散布前对 不同生境植株种子的产量进行调查, 每个生境分别 选 4 个 $1 \mathrm{~m} \times 1 \mathrm{~m}$ 的样方, 将样方中的植株全部取 回 统计单株的种子数量和样方中的种子数量 (种 子为完好种子:饱满、黑褐色、未被啃食), 种子风干 后用千分之一电子天平称其千粒重。

\section{2 种子库取样}

2001 年 5 月, 在种子成熟前,在不同生境样地 的植株附近选择 $0.5 \mathrm{~m} \times 0.5 \mathrm{~m}$ 的样方各 2 个,把表 层土 $(5 \mathrm{~cm})$ 全部取回, 带回实验室, 用篮分法统计 样方内种子数。7 月中旬, 当明党参、峨参种子刚散 布完毕时, 在不同生境样地中选择植株生长良好的 样方 $(1 \mathrm{~m} \times 1 \mathrm{~m})$ 共 16 个, 测量植株根部在样方内 的坐标。再将样方分成 25 个 $20 \mathrm{~cm} \times 20 \mathrm{~cm}$ 的小样 方取每个样方两条对角线上的小样方共 9 个, 将小 样方表层土 (包括枯枝落叶) 分别取出, 厚度 $2 \sim 5$ $\mathrm{cm}$ ( 种子落下后一般停在地层表面, 上有枯枝落叶 覆盖, 表层土较薄, 下面为硬土层), 装入样袋, 带回 实验室。用筛分法统计每个小样方内种子数, 做种 子库密度分析。同样方法, 选 $1 \mathrm{~m} \times 1 \mathrm{~m}$ 的样方, 将 25 个小样方的土样分别取回, 统计每个小样方内的 种子数, 做种子散布格局分析。同年 11 月, 按类似 方法再取一次样, 测定种子库的变化和萌发前的种 子库状况。

为了解明党参种子散布特征, 选择上方及周围 无其他明党参植株的单株明党参, 根据花葶倒伏的 方向及位置确定取样范围, 按面积大小分成 $20 \mathrm{~cm}$ $\times 20 \mathrm{~cm}$ 的小样方 15 个, 按上述方法将表层土取 回 统计小样方内种子数。

\section{3 数据处理}

将明党参、峨参种子库取样面积的种子数目换 算成 $1 \mathrm{~m}^{2}$ 面积的数量即为种子库的种子密度。分 别统计种子散布格局样方内的 25 个小样方种子数， 统计明党参单株各个小样方内的种子数。利用 Greig-Smith 邻接格子样方法研究种子散布格局 (谢 宗强等, 1999)。采用以下 2 种格局判定方法:

(1) 扩散系数: $C=s^{2} / x$, 又叫偏离系数, 其统计 学基础是泊松分布中方差 $\left(s^{2}\right)$ 与均值 $(n)$ 相等。均 
匀分布时, 抽样单位中出现的个体数 $(x)$ 接近于均 值, 方差小于均值; 集群分布时, 个体数大于或小于 均值, 方差大于均值。因此, $C=1$ 为随机分布; $C<1$ 为均匀分布; $C>1$ 为集群分布。该值的显著性可 用 $t$-检验 $(p<0.05)$ 。

$$
t=\frac{\frac{s^{2}}{x}-1}{\sqrt{ } 2 /(n-1)}
$$

(2) Morista 指数 :

$$
I=\frac{\sum x^{2}-\sum x}{\left(\sum x\right)^{2}-\sum x} \times n
$$

其中 , $I=1$ 为随机分布; $I<1$ 为均匀分布; $I>1$ 为集 群分布。I 值可表明个体在空间散布的非随机程度, 但与取样单位的最多和最少个体数有关。统计学上 用 $F$-统计来检验 $I$ 与实测值的差异 $(p<0.05): F=$ $I \times\left(\sum x-1\right)+n-\sum x$ 。

\section{3 结果与分析}

\section{1 种子生产}

明党参是多年生草本, 通常茎高 $1 \mathrm{~m}$ 左右, 个别 植株甚至可高于 $2 \mathrm{~m}$,但叶几乎全部为基生, 茎生叶 严重退化, 茎几乎就是花葶, 且中空, 长期浸水易腐 烂。复伞形花序顶生和侧生, 顶生花序结实率为 $71.11 \%$;侧生花序 $3 \sim 8$ 个,多数不育, 结实率只有 $16.57 \%$ (表 1 )。每株明党参平均产生完好种子 132 粒, 其中 $86.36 \%$ 来自顶生花序。

表 1 不同生境明党参顶生花序、侧生花序结实率 ( \%)

Table 1 Percent of the ripe seeds on the top and lateral inflorescences of Changium smyrnioides in different habitats

\begin{tabular}{ccc}
\hline $\begin{array}{c}\text { 生境 } \\
\text { Habitats }\end{array}$ & $\begin{array}{c}\text { 顶生花序 } \\
\text { Top inflorescence }\end{array}$ & $\begin{array}{c}\text { 侧生花序 } \\
\text { Lateral inflorescence }\end{array}$ \\
$\begin{array}{c}\text { 落叶阔叶林 } \\
\text { Deciduous broad- } \\
\text { leaved forest } \\
\text { 竹林 }\end{array}$ & $68.92 \pm 9.36$ & $14.8 \pm 8.44$ \\
Bamboo stand & $77.7 \pm 15.67$ & $4.79 \pm 3.10$ \\
\hline
\end{tabular}

千粒重是反映种子质量好坏的一个重要指标。 不同生境的明党参种子千粒重有差别，竹林下的千 粒重明显高于落叶阔叶林 (表 2)。种子重与植株总 重的比值在竹林下为 0.078 ,在落叶阔叶林下为 0.066 。在上方落叶树叶未展开之前，竹林下的光照 比落叶阔叶林下差, 且竹林下的地被物厚度也大, 因 此竹林下的明党参从萌发到生长, 条件比阔叶林下 稍差。竹林下明党参的种子投入比落叶阔叶林下的 明党参大 靠增加种子质量而在不良生境中生存。

\section{2 种子散布}

6 月下旬明党参种子全部成熟，地上部分枯萎， 茎 (花葶) 受外力 (风、雨、机械压力等) 影响易倒伏， 在此过程中种子开始散布,7月种子散布结束。明 党参植株生长较分散, 野外可以找到周围无其他明 党参植株的单株明党参。在竹林下选定单株生长良 好的明党参植株, 位于坡度为 $30^{\circ}$ 的斜坡上, 地表覆 盖着 $2 \sim 5 \mathrm{~cm}$ 厚的竹叶, 种子成熟时无伴生种, 植株 高度为 $110 \mathrm{~cm}$, 在 $1 \mathrm{~m}^{2}$ 的面积内共有 43 粒种子, 大 部分不在植株根部附近, 而是在花序附近。由此可 以推测，植株花蒙在种子散布开始前已经开始倒伏。 野外观察发现, 花葶倒伏的方向不受坡向的影响。 用 Greig-Smith 邻接格子样方法研究种子散布格局 的结果表明, 各样方的扩散指数、Morisita 指数均大 于 1 , 由此判定明党参样方及单株的种子散布格局 均为集群型 (表 3 )。

\section{3 种子库密度动态}

本文的种子库密度是指植株附近单位面积的土 壤中所储藏的种子数 (成熟完好种子)。经过测定， 2001 年 5 月底明党参种子未成熟时, 土壤种子库密 度为零。把散布前 (即 6 月初) 样方内植株上的种 子量作为土壤种子库的理论最大密度 (没有动物取 食、腐烂等情况发生)，7月中旬种子散布结束后的 种子密度作为散布后土壤种子库密度, 11 月中旬的 种子库密度作为萌发前土壤种子库密度, 结果见表 4 。

散布前落叶阔叶林和竹林下的最大种子库密度 差异显著 $(p<0.05)$,6 月初 (种子刚刚下落) 落叶 阔叶林下的种子库密度是竹林下的 2 倍。7 月初 (种子散布结束 1 周后) ,种子库密度已显著下降, 落叶阔叶林仅存留种子产量的 $3.01 \% \sim 4.31 \%$, 竹 林存留率最高为 $15.97 \%$ 。经过 3 个多月的再分 布 到 11 月中旬种子萌发前, 竹林下植株附近样方 内没有发现完好种子, 落叶阔叶林也仅存留最大种 子库密度的 $0.28 \% \sim 0.94 \%$ 。种子丢失主要有被 动物取食、腐烂及运输到远离母株的微生境等几种 可能 (李宏俊, 张知彬,2000)。把种子空壳看作是 被动物取食的种子, 葛岭的空壳数目和完好种子数 目为 $1: 1$, 南高峰为 1.2 : 1 。除去上述完好种子及 空壳, 其余的部分可认为是已经受病菌等微生物侵 染而腐烂在生境中, 这一部分大约占了当年种子的 $2 / 3$ 。 
表 2 明党参、峨参在不同生境中的种子千粒重

Table 2 Seed kilo-grain weight of Changium smyrnioides and Anthriscus sylvestris in different habitats

\begin{tabular}{|c|c|c|c|c|}
\hline $\begin{array}{c}\text { 物种 } \\
\text { Species }\end{array}$ & $\begin{array}{c}\text { 生境 } \\
\text { Habitats }\end{array}$ & $\begin{array}{c}\text { 千粒重 } \\
\text { Kilo-grain weight of seeds }(\mathrm{g})\end{array}$ & $P$ & $P$ \\
\hline Changium smyrnioides & $\begin{array}{l}\text { 落叶阔叶林 Deciduous broad-leaved forest } \\
\text { 竹林 Bamboo stand }\end{array}$ & $\begin{array}{l}4.145 \pm 0.808 \\
5.396 \pm 0.560\end{array}$ & 0.139 & \multirow{2}{*}{$* * *$} \\
\hline Anthriscus sylvestris & $\begin{array}{l}\text { 落叶阔叶林 Deciduous broad-leaved forest } \\
\text { 路边 Roadside }\end{array}$ & $\begin{array}{l}1.655 \pm 0.006 \\
2.203 \pm 0.005\end{array}$ & 0.296 & \\
\hline
\end{tabular}

*** $p<0.001$

表 3 明党参、峨参种子散布格局

Table 3 Patterns of seed dispersal of Changium smyrnioides and Anthriscus sylvestris

\begin{tabular}{|c|c|c|c|c|c|c|c|}
\hline \multirow{2}{*}{$\begin{array}{l}\text { 类型 } \\
\text { Type }\end{array}$} & \multirow{2}{*}{$\begin{array}{c}\text { 种子数 } \\
\text { No. of seeds } \\
n\end{array}$} & \multicolumn{3}{|c|}{ 扩散系数 Dispersal index } & \multicolumn{3}{|c|}{ Morisita 指数 Morista index } \\
\hline & & $s^{2} / x$ & $t$ & $\begin{array}{c}\text { 格局 } \\
\text { Pattern }\end{array}$ & $I$ & $F$ & $\begin{array}{c}\text { 格局 } \\
\text { Pattern }\end{array}$ \\
\hline \multicolumn{8}{|c|}{ Changium smyrnioides } \\
\hline 样方 1 Sample 1 & 36 & 3.419 & 8.380 & $\mathrm{c}^{* *}$ & 2.659 & 82.056 & $\mathrm{c}^{* *}$ \\
\hline 样方 2 Sample 2 & 60 & 6.771 & 19.991 & $\mathrm{c}^{* *}$ & 3.347 & 162.500 & $\mathrm{c}^{* *}$ \\
\hline 单株 Single & 43 & 6.525 & 17.029 & $\mathrm{c}^{* *}$ & 3.499 & 123.977 & $\mathrm{c}^{* *}$ \\
\hline \multicolumn{8}{|l|}{ Anthriscus sylvestris } \\
\hline 样方 Sample & 1354 & 21.874 & 72.311 & $\mathrm{c}^{* *}$ & 1.246 & 524.985 & $\mathrm{c}^{* *}$ \\
\hline
\end{tabular}

** : Contagious distribution

表 4 明党参、峨参不同时期不同生境种子库密度

Table 4 The density of seed banks of Changium smyrnioides and Anthriscus sylvestris in different stages and habitats

\begin{tabular}{|c|c|c|c|c|c|c|c|}
\hline $\begin{array}{c}\text { 物种 } \\
\text { Species }\end{array}$ & $\begin{array}{c}\text { 生境 } \\
\text { Habitats }\end{array}$ & $\begin{array}{c}\text { 散布前 } \\
\text { Pre-dispersal } \\
\left(\text { Seed } / \mathrm{m}^{2}\right)\end{array}$ & $P$ & $\begin{array}{c}\text { 散布后 } \\
\text { Post-dispersal } \\
(\text { Seeds/m²) }\end{array}$ & $P$ & $\begin{array}{c}\text { 萌发前 } \\
\text { Pre-germination } \\
\left(\text { Seeds } / \mathrm{m}^{2}\right)\end{array}$ & $P$ \\
\hline $\begin{array}{l}\text { Changium } \\
\text { smyrnioides }\end{array}$ & $\begin{array}{l}\text { 落叶阔叶林 Deciduous broad-leaved forest } \\
\text { 竹林 Bamboo stand }\end{array}$ & $\begin{array}{l}465.1 \pm 220.7 \\
251.6 \pm 87.2\end{array}$ & $* *$ & $\begin{array}{l}23.8 \pm 19.3 \\
24.9 \pm 4.1\end{array}$ & 0.158 & $\begin{array}{l}3.6 \pm 0 \\
0.0\end{array}$ & 0.073 \\
\hline $\begin{array}{l}\text { Anthriscus } \\
\text { sylvestris }\end{array}$ & $\begin{array}{l}\text { 落叶阔叶林 Deciduous broad-leaved forest } \\
\text { 路边 Roadside }\end{array}$ & $\begin{array}{l}13139.4 \pm 3724.9 \\
19044.7 \pm 2651.2\end{array}$ & 0.129 & $\begin{array}{c}1961.1 \pm 0.0 \\
1354.4 \pm 659.9\end{array}$ & 0.509 & $\begin{array}{l}105.0 \pm 42.4 \\
122.5 \pm 95.5\end{array}$ & 0.835 \\
\hline
\end{tabular}

\section{4 讨论与结论}

与明党参相比,峨参茎较粗壮, 多分枝, 茎生叶 发达, 顶生和侧生花序之间的种子结实率没有显著 差异，种子成熟时间略早，种子千粒重低(是明党参 的 $1 / 2$ 甚至 $1 / 3$,见表 2 ), 但种子数量多，每株平均 产生完好种子 1150 粒, 是明党参 (132 粒) 的近 10 倍, 且峨参的根可繁殖出无性系小株, 形成密集生长 的植株丛 (平均 7 株/丛,最多可达 9 株/丛)，大大 增强了其繁殖能力。

峨参植株在种子散布过程中不会倒伏, 大部分 种子散布在母株丛附近,种子散布格局也是聚集型 (表 3 )。虽然峨参种子从成熟到萌发这段时间种子 丢失情况也非常严重,但就种子数量而言,萌发前 114 粒 $/ \mathrm{m}^{2}$ 的完好种子库还是比较丰富的 (表 4 )。
种子库的种子数量来自下落的母株种子, 因此 母株的种子产量是影响种子库密度的首要因素。在 植株分布密、生长好的地方, 种子库密度相对较高。 落叶阔叶林下明党参植株分布密度为平均 3 4 株/ $\mathrm{m}^{2}$, 竹林下为平均 2 株 $/ \mathrm{m}^{2}$, 故落叶林下的明党参种 子库密度比竹林下高。同样, 路边生境中峨参植株 分布密度为平均 4 丛 $/ \mathrm{m}^{2}\left(28\right.$ 株 $\left./ \mathrm{m}^{2}\right)$,林下为平均 3 丛 $/ \mathrm{m}^{2}\left(21\right.$ 株 $\left./ \mathrm{m}^{2}\right)$, 路边的种子库密度高于林下。 除了母株密度外, 种群的种子产量还受植株大小的 影响。植株的年龄及环境质量会影响植株大小, 同 样也对分配给生殖的资源产生直接影响 (Nathan, $2000)$ 。明党参植株寿命长,一生可以多次生殖; 峨 参植株寿命短, 营养生长 $2 \sim 3$ 年, 开花结实后主根 死亡, 但一次投入种子生产的资源比例 (种子重/植 株总重) 是明党参的 2.6 倍。 
动物对种子的取食造成一定数量的种子丢失 ( Janzen ,1971; 李宏俊, 张知彬, 2001) , 在不同的微 生境中，动物对种子的捕食率各不相同（Schupp $1995)$ ，在每次观察中都发现有明党参种子的空壳 存在于土壤中，7 月中旬空壳比例为 $27.8 \%, 11$ 月 中旬比例为 $45 \%$ 。阔叶林下的空壳数量多于竹林 下。Blate et al. (1998) 提出, 分散的单个种子扩散 后的被捕食速率可能强烈影响雨林中树木的种群动 态和生活史进化。峨参种子由于形状细长, 重量较 轻, 所含营养物质相对较少, 与明党参种子相比受动 物取食的可能性较小，试验中也未见种子空壳。明 党参和峨参种子被食的比例还需进一步研究。

在明党参、峨参种子未成熟时, 土壤中没有发现 往年存留下来的种子, 这意味着 2 个种的种子库内 皆是当年形成的新种子。种子萌发实验表明, 明党 参、峨参种子在干燥条件下贮藏, 失去活性不能萌 发; 在湿润条件下陉藏,有活性的种子会全部萌发， 不能存财到第 2 年。因此初步推断明党参、峨参种 子在自然条件下生理活性只有 1 年, 它们属于非持 续的种子库类型 (Nathan, 2000)。与那些种子活力 能保持多年的植物相比, 明党参土壤种子库的潜在 发展能力较小。当然, 明党参植株可以多次生殖, 可 维持每年的种子库，弥补了种子库不持续问题。峨 参种子库也是非持续种子库, 它可以产生无性系, 通 过无性系来繁殖，以弥补种子库的不足。

从种子生产和散布方面看, 明党参采取的是低 种子数量、大粒种子、远离母株散布以避免幼苗强竞 争的生殖对策，应属于 $K$ 对策种。尽管明党参这种 特性能降低种内的竞争增加种子存活、萌发及成长 的机会, 但是种子密度低就会使种群发展的速度受 到限制, 特别是受到人类强度采挖和破坏生境后恢 复起来比较困难。峨参主根生活 $2 \sim 3$ 年开花结实 1 次后死亡, 产生 4 9 个无性系, 来年形成新的个 体，在繁殖上的投入较高，种子数量多，密集分布在 母株附近，应属于 $r$ 对策种。由于具有能产生大量 种子及无性系的双重机制，峨参在受到人类采挖后 可以快速恢复种群, 因而没有出现濒危现象。

\section{参考文献}

程翔, 黄致远, 宋世贤, 1993. 珍稀中药材明党参生态地理 分布、利用与保护. 中国中药杂志, 18(6)：327 329 国家环保局, 中国科学院植物研究所, 1991. 稀有濒危植物
的保护和研究. 北京: 环境科学出版社, $187 \sim 188$ 李宏俊, 张知彬, 2000. 动物与植物种子更新的关系 I. 对

象、方法和意义. 生物多样性, 8(4) : 405 412

李宏俊, 张知涁, 2001. 动物与植物种子更新的关系 II. 动 物对种子的捕食、扩散、咜藏及与幼苗建成的关系. 生 物多样性, 9(1):25 37

刘济明, 钟章成, 2000. 梵净山栲树群落的种子雨、种子库 及更新. 植物生态学报, 24(4):402 407

潘泽惠，余孟兰，刘心恬，姚欣梅，1995. 中国伞形科特有 属核型演化及地理分布. 植物资源与环境, 4(3)：1 8 邱英雄，傅承新，2001. 明党参的濒危机制及其保护对策的 研究. 生物多样性, 9(2): 151 156

舒璞, 余孟兰, 1990. 中国伞形科特有属的花粉形态学研 究. 江苏科学技术出版社, $33 \sim 36$

孙书存, 陈灵芝, 2000. 东灵山地区辽东栎种子库统计. 植 物生态学报, 24(2):215 221

唐勇, 曹敏, 张建侯, 盛才余, 1998. 西双版纳白背桐次生 林土壤种子库、种子雨研究. 植物生态学报, 22(6): 505 $\sim 512$

谢宗强, 陈伟烈, 刘正宇, 江明喜, 黄汗东, 1999. 银杉种 群的空间分布格局. 植物学报, 41(1)：95 101

杨允菲, 祝玲, $1995 \mathrm{a}$. 松嫩平原碱化草甸朝鲜碱茅种子散 布机制的分析. 植物学报, 37(3):222 230

杨允菲, 祝玲, $1995 \mathrm{~b}$. 松嫩平原盐碱植物群落种子库的比 较分析. 植物生态学报, 19(2): 144 148

Berg H, 2000. Differential seed dispersal in Oxalis acetosella, a cleistogamous perennial herb. Acta Oecologica, 21 (2): $109 \sim 118$

Blate G M, D R Peart and M Leighton, 1998. Post-dispersal predation on isolated seeds: a comparative study of 40 tree species in a Southeast Asian rainforest. Oikos, 82: 522 538

Hall J B and M D Swaine, 1980. Seed stocks in Ghanainan forest soils. Biotropica, 12: $256 \sim 268$

Janzen D H, 1971. Seed predation by animals. Annual Review of Ecology and Systematics, 2: $465 \sim 492$

Marchand P J and D A Roach, 1980. Reproductive strategies of pioneering alpine species: seed production, dispersal, and germination. Arctic and Alpine Research, 12: $137 \sim 146$

Nathan R, 2000. Spatial patterns of seed dispersal, their determinants and consequences for recruitment. Trends in Ecology and Evolution, 15(7): $278 \sim 285$

Platt W J, 1975. The colonization and formation of equilibrium plant species associations on bedger disturbances in a tallgrass prairie. Ecological Monograph, 45: 285 301

Sheldon J C and F M Burrows, 1973. The dispersal effectiveness of the achene-pappus units of selected compositea in steady winds with convection. New Phytologist, 72: 665 675

Schupp E W, 1995. Seed seedling conflicts, habitats choice, and patterns of plant recruitment. American Journal of Botany, 82: $399 \sim 409$ 